\title{
Method to compare water content values determined on the basis of different oven-drying temperatures
}

\author{
B. C. O’KELLY*
}

\author{
KEYWORDS: laboratory tests; soils; temperature effects; \\ standards
}

\section{INTRODUCTION}

The water content, $w$, is defined in geotechnical literature as the ratio of the mass of the pore water, $m_{\mathrm{w}}$, to the mass of the dry solid particles, $m_{\mathrm{s}}$, given as a percentage. The pore water is the bulk water in the voids between the solid particles. The oven-drying method (BSI, 1990a; ASTM, 1998 ) is the preferred method for laboratory determination of the water content, calculated as the ratio of the reduction in the total mass of the test specimen to its equilibrium oven-dried mass $m_{\mathrm{D}}$, given as a percentage:

$$
w=\frac{m_{\mathrm{w}}}{m_{\mathrm{D}}} \times 100(\%)
$$

The method assumes that the reduction in the total mass is due to the complete evaporation of the pore water alone, and the specimens are oven dried at $105 \pm 5^{\circ} \mathrm{C}$ (BSI, $1990 \mathrm{a})$ or $110 \pm 5^{\circ} \mathrm{C}$ (ASTM, 1998) for complete evaporation to occur. However, the value of the water content can depend on the oven-drying temperature $t$. A reduction in the mass of the dry solid particles, $\Delta m_{\mathrm{D}}$, may occur at the standard oven-drying temperatures, generally as a result of charring but also occasionally because of the loss of water of crystallisation. For example, MacFarlane \& Allen (1963) and O'Kelly (2005) reported that peat and other highly organic soils experienced some slight charring at drying temperatures above $85^{\circ} \mathrm{C}$. The water of crystallisation in gypsum, for example, is removed by heating above $100^{\circ} \mathrm{C}$. Hence the true value of the water content given by equation (1) is overestimated $\left(w_{\text {high }}\right)$ for such soils when determined on the basis of the specimen mass corresponding to the standard oven-drying temperatures of $105^{\circ} \mathrm{C}$ or $110^{\circ} \mathrm{C}$ :

$$
w_{\text {high }}=\frac{m_{\mathrm{w}}+\Delta m_{\mathrm{D}}}{m_{\mathrm{D}}-\Delta m_{\mathrm{D}}} \times 100(\%)\left(t \geqslant 100^{\circ} \mathrm{C}\right)
$$

Lower oven-drying temperatures, typically $60^{\circ} \mathrm{C}$ or $80^{\circ} \mathrm{C}$, are often used for water content determinations on such soils (Jarrett, 1983). However, small quantities of residual pore water, $\Delta m_{\mathrm{w}}$, can remain in the specimen when it is dried at temperatures below $100^{\circ} \mathrm{C}$, and the true value of the water content is underestimated ( $\left.w_{\text {low }}\right)$ when determined on the basis of the specimen mass corresponding to an oven-drying temperature below $85^{\circ} \mathrm{C}$ :

Manuscript received 19 July 2004; revised manuscript accepted 21 February 2005.

Discussion on this paper closes on 1 November 2005, for further details see p. ii.

* Department of Civil, Structural and Environmental Engineering, University of Dublin, Trinity College, Ireland (formerly Scott Wilson Consulting Engineers, UK).

$$
w_{\text {low }}=\frac{m_{\mathrm{w}}-\Delta m_{\mathrm{w}}}{m_{\mathrm{D}}+\Delta m_{\mathrm{w}}} \times 100(\%)\left(t<85^{\circ} \mathrm{C}\right)
$$

The true value of the water content is calculated on the basis of the oven-drying temperature between $85^{\circ} \mathrm{C}$ and $100^{\circ} \mathrm{C}$ for which the mass of residual pore water exactly balances the reduction in the mass of the dry solid particles due to some charring or loss of water of crystallisation, and an experimental technique was presented by O'Kelly (2005) to identify this particular drying temperature.

The level of variability in water content values calculated for the same material but on the basis of different ovendrying temperatures is unclear. The purpose of this study was to examine the susceptibility of the solid particles in different soils to charring or slaking over the typical range of oven-drying temperatures used in practice. An experimental technique that facilitates direct comparison of water content values calculated on the basis of different ovendrying temperatures, and which draws on earlier studies by Skempton \& Petley (1970), is presented.

\section{TEST MATERIALS}

Oven-drying tests were conducted on nine soils, labelled $1-9$, and listed in Table 1 in order of increasing values of the loss on ignition (LOI) ratio. The LOI ratios were calculated as the reduction in the masses of the dry, powdered test specimens when ignited in a furnace at $440^{\circ} \mathrm{C}$ over a period of $18 \mathrm{~h}$, in accordance with BSI (1990b). The LOI value is a fairly accurate measure of the organic content, although some slight slaking or loss of water of crystallisation of the solid particles can also occur at $440^{\circ} \mathrm{C}$, which may account for the relatively high LOI values recorded for the marls (3-6). The level of biodegradation of the peats was quantified using the von Post classification system (von Post, 1924). Peat-1 was only very slightly degraded, and peat-2 was slightly degraded (H3 and H4 respectively, on the scale of von Post). The organic clay was dewatered sewage sludge material from a wastewater treatment plant, and had been used in a previous oven-drying study by O'Kelly (2005).

\section{EXPERIMENTAL PROCEDURE}

The test specimens were dried to constant mass at a series of oven temperatures that increased in value over the range $60-150^{\circ} \mathrm{C}$. The first value corresponds to the lower end of the drying temperature range used for water content determinations. The wet mass of each specimen was about $40 \mathrm{~g}$. The temperature in the oven chamber was thermostatically controlled and maintained within $1.5 \mathrm{deg} \mathrm{C}$ of the set temperature value. Oven drying continued at each test temperature until the dry masses of the specimens had equilibrated, which was established by recording the specimen masses to $0.01 \mathrm{~g}$, usually at $4 \mathrm{~h}$ intervals. For example, Fig. 1 shows the reduction in the mass of the peat- 2 specimen recorded 
Table 1. Some index properties of test soils

\begin{tabular}{l|c|c|c|c|c}
\hline Label & Soil type & Liquid limit: $\%$ & Plastic limit: \% & Specific gravity & LOI (ratio) \\
\hline 1 & Silt & 65 & 32 & $2 \cdot 66$ & $0 \cdot 03$ \\
2 & Clay & 83 & 35 & $2 \cdot 70$ & $0 \cdot 06$ \\
3 & Marl-1 & 116 & 95 & $2 \cdot 22$ & $0 \cdot 07$ \\
4 & Marl-2 & 131 & 106 & $2 \cdot 41$ & $0 \cdot 07$ \\
5 & Shelly marl & 107 & 139 & $2 \cdot 35$ & $0 \cdot 10$ \\
6 & Organic marl & 180 & 53 & $1 \cdot 55$ & $0 \cdot 30$ \\
7 & Organic clay & 315 & 310 & $1 \cdot 19$ & $0 \cdot 70$ \\
8 & Peat-1 (H3) & 900 & 485 & $1 \cdot 47$ & $0 \cdot 88$ \\
9 & Peat-2 (H4) & 735 & & $0 \cdot 93$ \\
\hline
\end{tabular}

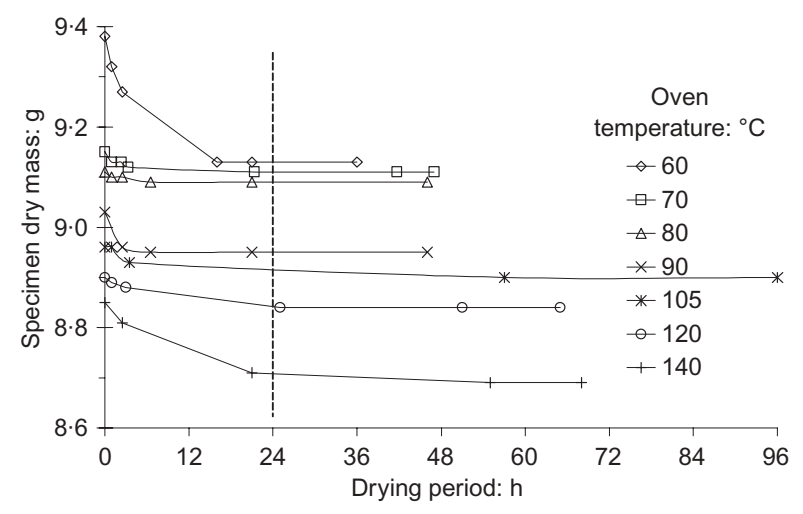

Fig. 1. Dry mass of peat-2 against oven-drying period

for the different oven-drying temperatures. The specimens were allowed to cool in a desiccator container to the ambient laboratory temperature of $21^{\circ} \mathrm{C}$ before being weighed. After each weighing, the specimens were replaced in the same locations in the drying oven. Longer drying periods, although still generally less than $24 \mathrm{~h}$ duration, were required for the dry masses of the specimens to equilibrate for oven temperatures below $100^{\circ} \mathrm{C}$.

\section{EXPERIMENTAL RESULTS}

The susceptibility of the solid particles to charring with increasing oven-drying temperature was assessed in terms of the reduction in the equilibrium dry mass, expressed as a percentage of the oven dry mass initially recorded at $60^{\circ} \mathrm{C}$. The test data are plotted in Fig. 2 for the different soils.

The range of reductions in the equilibrium dry masses of the inorganic specimens (silt, clay and marls 3 and 4) appears to be between $0 \cdot 3 \%$ and $0 \cdot 5 \%$ over the drying

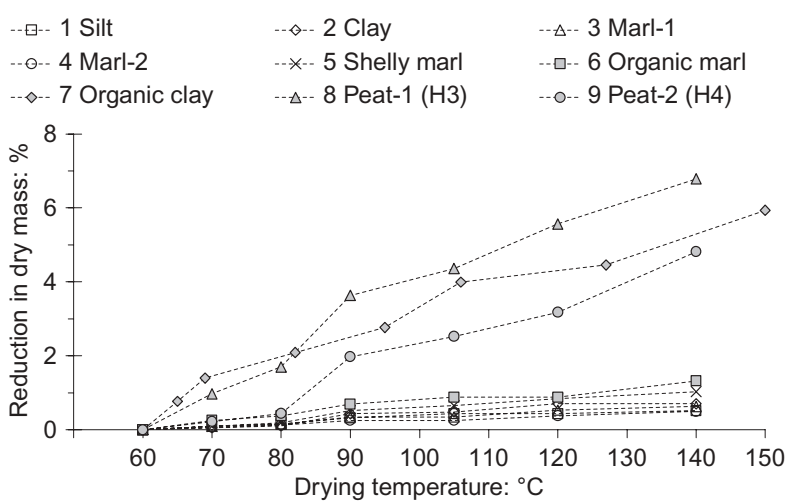

Fig. 2. Reduction in equilibrium dry mass against oven temperature temperature range $60-105^{\circ} \mathrm{C}$, indicating that the level of charring was not significant, whereas for the more organic soils the range is $3-5 \%$. The biggest reduction over this temperature range, of $4.4 \%$ dry mass, occurred for peat- 1 . The higher level of susceptibility of the organic soils is consistent with their higher LOI ratios and the fact that they were only very slightly to slightly degraded in the undisturbed condition. Similar reductions of up to about $1.0 \%$ dry mass recorded for the shelly marl (5) and organic marl (6) may be explained by greater slaking occurring for the more recently formed shell particles with increasing drying temperature.

Other observations from Fig. 2 include the change in the gradients of the different drying curves for oven temperatures of between $80^{\circ} \mathrm{C}$ and $90^{\circ} \mathrm{C}$. This was most likely due to the commencement of some slight charring, as reported for other peats and organic clays by MacFarlane \& Allen (1963) and O'Kelly (2005), or to slaking of the solid particles. The smaller reductions in the equilibrium dry masses recorded for oven temperature values increasing over the range $60-80^{\circ} \mathrm{C}$ were most likely due to the evaporation of residual amounts of pore water from the voids.

\section{METHODS TO COMPARE WATER CONTENT VALUES DETERMINED FOR DIFFERENT OVEN-DRYING TEMPERATURES}

Two methods are presented. Method A allows the direct comparison of water content values calculated on the basis of different drying temperatures, and uses oven-drying test data particular to the soil. Method B allows the prediction of water content values corresponding to different oven-drying temperatures using empirical sensitivity factors.

Method A: Calculation using data from oven-drying tests

The water content value $w_{t}$, corresponding to an ovendrying temperature $t^{\circ} \mathrm{C}$, can be calculated from $w_{105^{\circ}} \mathrm{C}$, the water content value measured on the basis of the standard oven-drying temperature of $105^{\circ} \mathrm{C}$, using equation (4). The background to equation (4) is presented in Appendix 1.

$$
w_{t}=\alpha_{t}\left(w_{105^{\circ} \mathrm{C}}+1\right)-1 \text { (as decimal) }
$$

where the water content parameter $\alpha_{t}=m_{\mathrm{D}, 105^{\circ} \mathrm{C}} / m_{\mathrm{D}, t} ; m_{\mathrm{D}, t}$ and $m_{\mathrm{D}, 105^{\circ} \mathrm{C}}$ are the equilibrium oven dry masses corresponding to drying temperatures $t$ and $105^{\circ} \mathrm{C}$ respectively.

More generally:

$$
w_{t 2}=\frac{\alpha_{t 2}\left(w_{t 1}+1\right)}{\alpha_{t 1}}-1 \text { (as decimal) }
$$

where subscripts $t 1$ and $t 2$ are different oven-drying temperatures.

An $\alpha_{t}$ parameter value of unity would indicate that the true value of the water content would be determined for any 
oven-drying temperatures in the range $t$ to $105^{\circ} \mathrm{C}$. Fig. 3 shows the $\alpha_{t}$ parameter values for the different soils plotted against the drying temperature. The values for the silt, clay and marls (1-5), Fig. 3(a), are very close to unity and indicate, for practical purposes, that water content values calculated on the basis of different oven-drying temperature within the range $60-140^{\circ} \mathrm{C}$ are accurate, and can be directly compared. However, the $\alpha_{t}$ parameter values calculated for the more organic soils (6-9), Fig. 3(b), are more significant, being almost an order of magnitude greater.

Water content values for different drying temperatures can be directly compared using equations (4) and (5) and the data presented in Fig. 3. For example, the water content of peat-1 corresponding to an oven-drying temperature of $60^{\circ} \mathrm{C}$ can be calculated from the value measured at the standard drying temperature of $105^{\circ} \mathrm{C}$ using $\alpha_{60^{\circ} \mathrm{C}}=0.956$ in equation (4). Alternatively, the same water content value will be calculated from the value measured for an oven-drying temperature of, for example, $80^{\circ} \mathrm{C}$ using $\alpha_{60^{\circ} \mathrm{C}}=0.956$ and $\alpha_{80{ }^{\circ} \mathrm{C}}=0.973$ in equation (5).

\section{Method B: Prediction using sensitivity factors}

The amount of pore water that remains in the voids for $t<100^{\circ} \mathrm{C}$, and the level of susceptibility of the solid particles to charring for $t>85^{\circ} \mathrm{C}$, are approximately related to the organic content, which can be quantified fairly accurately in terms of the LOI ratio. The $\alpha_{t}$ values shown in Fig. 4 have been normalised using the LOI ratios listed in Table 1 for the different soils. It was found that for LOI $\geqslant$ 0.05 the normalised data were bounded above and below by lines with gradients, $\beta$, of 0.0005 and $0 \cdot 0015$. Further tests on other soils may refine these limiting $\beta$ values. Based on these correlations, the following empirical relationship exists:

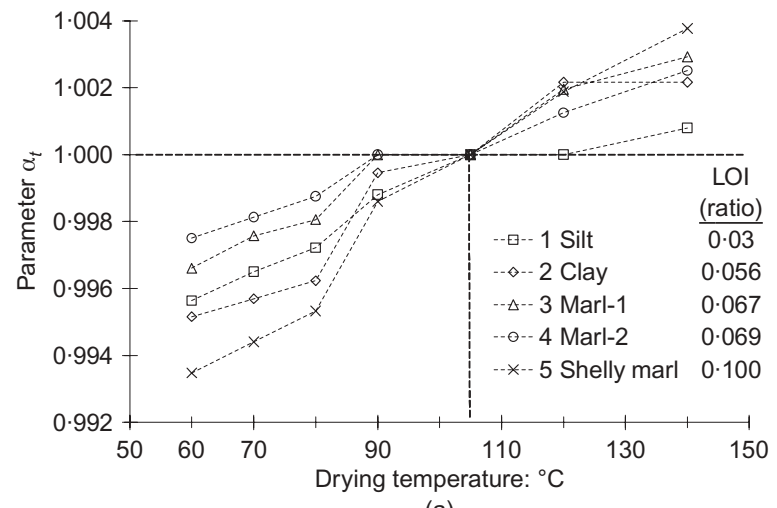

(a)

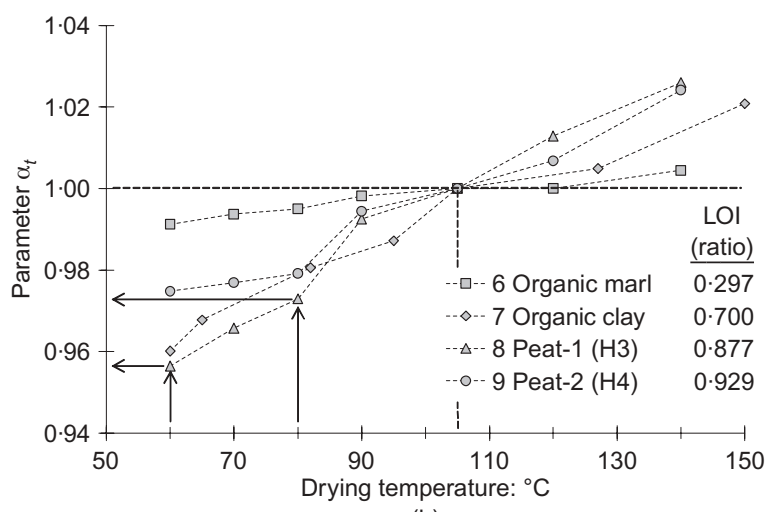

(b)

Fig. 3. Parameter $\alpha_{t}$ against oven-drying temperature: (a) silt, clay and marls; (b) peats, organic clay and organic marl

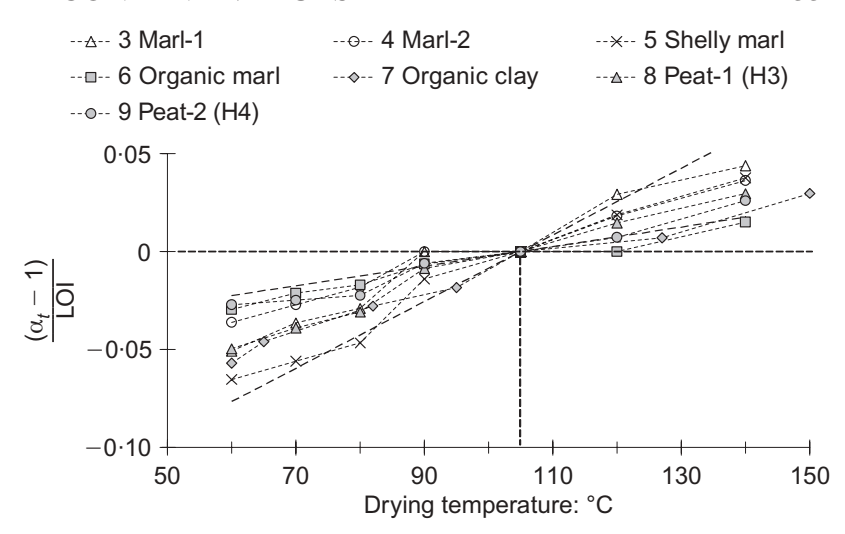

Fig. 4. Normalised parameter $\alpha_{t}$ against oven-drying temperature

$$
\frac{\left(\alpha_{t}-1\right)}{\mathrm{LOI}}=\beta(t-105) \quad(\mathrm{LOI} \geqslant 0 \cdot 05, \text { as decimal })
$$

where $\beta$ is an empirical sensitivity factor with values in the range $0 \cdot 0005-0 \cdot 0015$, and $t$ is the oven-drying temperature $\left(t \geqslant 60^{\circ} \mathrm{C}\right)$.

Rearranging equation (6), an appropriate $\alpha_{t}$ value can be estimated as follows, and used in equations (4) or (5) for water content comparisons on a specific soil:

$$
\alpha_{t}=1+\beta \cdot \operatorname{LOI}(t-105) \quad(\mathrm{LOI} \geqslant 0 \cdot 05, \text { as decimal) }
$$

The same range of $\beta$ values was found to apply when the data for the marls (3-6) and the more organic soils (7-9) were analysed separately. The level of susceptibility of organic material to charring appeared to be approximately inversely related to its state of biodegradation. For example, $\beta$ was 0.0012 for the fresh sludge material (7), and 0.0011 and 0.0007 for the very slightly degraded (8) and slightly degraded (9) peat materials respectively. These values were determined from least squares curve fitting of the test data in Fig. 4. The different $\beta$ values for the marls (3-5) may be explained in terms of different levels of susceptibility to some slaking due to their geological age, with $\beta=0.0015$ for the more recent shelly marl (5), and 0.0011 and 0.0008 for marl-1 and marl-2 respectively.

\section{SUMMARY AND CONCLUSIONS}

The dry mass of a test specimen generally decreases for higher oven-drying temperatures as a result of small amounts of residual pore water evaporating from the void space $(t<$ $100^{\circ} \mathrm{C}$ ), and some slight charring or slaking of the solid particles $\left(t>85^{\circ} \mathrm{C}\right)$. Hence the apparent water content determined using the oven-drying method generally increases for higher oven-drying temperatures.

The reductions in the dry masses of between $0.3 \%$ and $0.5 \%$ for the specimens of silt, clay and marl (ignition loss LOI, ratios less than 0.05) were not significant over the drying temperature range of $60-105^{\circ} \mathrm{C}$. Hence the water content values of these soils are, for practical purposes, independent of the oven-drying temperature used. However, the reductions in the dry masses of the shelly and organic marls and peats tested were significant, at up to $4.4 \%$ dry mass at $105^{\circ} \mathrm{C}$ in the case of the peat material.

Two methods were presented to relate and standardise water content values determined for the same material but on the basis of different oven-drying temperatures. The first method uses a water content parameter $\alpha_{t}$, defined as the ratio of the specimen dry masses at $105^{\circ} \mathrm{C}$ and $t^{\circ} \mathrm{C}$, and which is determined from a series of drying tests at different oven temperatures. The second method uses an empirical 
correlation based on the LOI ratio, and a sensitivity factor $\beta$.

\section{APPENDIX 1}

The total mass $m$ of the test specimen is given by

$$
m=m_{\mathrm{w}}+m_{\mathrm{D}}
$$

where $m_{\mathrm{w}}$ and $m_{\mathrm{D}}$ are the mass of the pore water and the equilibrium oven-dried mass respectively.

The water content $w$ is calculated in geotechnical literature as

$$
w=\frac{m_{\mathrm{w}}}{m_{\mathrm{D}}}(\text { as decimal })
$$

Substituting $\left(m-m_{\mathrm{D}}\right)$ for $m_{\mathrm{w}}$, from equation (8):

$$
w=\frac{m}{m_{\mathrm{D}}}-1
$$

Values of the water content $w_{105^{\circ} \mathrm{C}}$, corresponding to the standard oven-drying temperature of $105^{\circ} \mathrm{C}$, and $w_{t}$, corresponding to an oven-drying temperature of $t^{\circ} \mathrm{C}$, are given by

$$
\begin{aligned}
& w_{105^{\circ} \mathrm{C}}=\frac{m}{m_{\mathrm{D}, 105^{\circ} \mathrm{C}}}-1 \\
& w_{t}=\frac{m}{m_{\mathrm{D}, t}}-1
\end{aligned}
$$

where $m_{\mathrm{D}, t}$ and $m_{\mathrm{D}, 105^{\circ} \mathrm{C}}$ are the equilibrium dry masses corresponding to oven-drying temperatures of $t$ and $105^{\circ} \mathrm{C}$ respectively.

Water content calculations equate the loss in the mass of the dry solid particles to the evaporation of pore water. Hence, for the purposes of the calculation, there is a perceived conservation of the total mass of the specimen.

Rearranging equations (10a) and (10b):

$$
\begin{aligned}
& m=w_{105^{\circ} \mathrm{C}} m_{\mathrm{D}, 105^{\circ} \mathrm{C}}+m_{\mathrm{D}, 105^{\circ} \mathrm{C}} \\
& =w_{t} m_{\mathrm{D}, t}+m_{\mathrm{D}, t}
\end{aligned}
$$

Rearranging equations (11a) and (11b), the value of the water content $w_{t}$ is given by

$$
w_{t}=\alpha_{t}\left(w_{105^{\circ} \mathrm{C}}+1\right)-1 \text { (as decimal) }
$$

where $\alpha_{t}=m_{\mathrm{D}, 105^{\circ} \mathrm{C}} / m_{\mathrm{D}, t}$.
NOTATION

LOI loss in dry mass on ignition ratio

$m$ total mass of specimen

$m_{\mathrm{D}}$ equilibrium oven-dried mass

$\Delta m_{\mathrm{D}}$ reduction in mass of dry solid particles

$m_{\mathrm{s}} \quad$ mass of dry solid particles

$m_{\mathrm{W}}$ mass of pore water

$\Delta m_{\mathrm{w}}$ mass of pore water remaining in the voids

$w$ water content

$\alpha_{t} \quad$ water content parameter

$\beta$ sensitivity factor

$\sigma_{\mathrm{v}}^{\prime} \quad$ vertical effective stress

\section{Subscripts}

$t$ oven-drying temperature of $t^{\circ} \mathrm{C}$

$t 1, t 2$ different oven-drying temperatures

$105^{\circ} \mathrm{C}$ oven-drying temperature of $105^{\circ} \mathrm{C}$

\section{REFERENCES}

ASTM (1998). Standard test method for laboratory determination of water (moisture) content of soil and rock by mass, D 2216. Philadelphia: American Society for Testing and Materials.

BSI (1990a). Methods of test for soils for civil engineering purposes: Classification tests, BS 1377-2. Milton Keynes: British Standards Institution.

BSI (1990b). Methods of test for soils for civil engineering purposes: Chemical and electro-chemical tests, BS 1377-3. London: British Standards Institution.

Jarrett, P. M. (1983). Testing of peats and organic soils, ASTM STP 820. Philadelphia: American Society for Testing and Materials.

MacFarlane, I. C. \& Allen, C. M. (1963). An examination of some index test procedures for peat. Proc. 9th Muskeg Res. Conf., Quebec.

O'Kelly, B. C. (2005). New method to determine true water content of organic soil. Geotech. Test. J. 28, No. 4, forthcoming (July).

Skempton, A. W. \& Petley, D. J. (1970). Ignition loss and other properties of peats and clays from Avonmouth, King's Lynn and Cranberry Moss. Géotechnique 20, No. 4, 343-356.

von Post, L. (1924). Das genetische System der organogenen Bildungen Schwedens. Int. Comm. Soil Science IV Commission, 287-304. 